$16^{\text {th }}$ International Conference on

AEROSPACE SCIENCES \& AVIATION TECHNOLOGY,

ASAT - 16 - May 26 - 28, 2015, E-Mail: asat@ mtc.edu.eg

Military Technical College, Kobry Elkobbah, Cairo, Egypt

Tel : +(202) 24025292 - 24036138, Fax: +(202) 22621908

\title{
Modeling and Simulation for Free Fall Bomb Dynamics in Windy Environment
}

\author{
Aly S. Atallah ${ }^{1}$, Gamal A. El-Sheikh ${ }^{2}$, Alaa El-Din S.Mohamedy ${ }^{3}$, Ahmed T. Hafez ${ }^{4}$ \\ ${ }^{1}$ M.Sc. Candidate, Military Technical College, Egypt \\ ${ }^{2}$ Professor, Pyramids high institute for Engineering and Technology, Egypt \\ ${ }^{3}$ Dr, EAF Researches and Development Branch, Egypt \\ ${ }^{4}$ Dr, Military Technical College, Egypt
}

\begin{abstract}
The main goal of aircraft bombing is its success in the destruction of the required target depending on the correct aiming and the correct moment of release. Different conditions, such as air speed, altitude, angle of release and the presence of wind, have a significant effect on the choice of the release moment to ensure target destruction. In this paper, a Six-degree of freedom (6DOF) mathematical model for the free fall bomb is presented describing the motion of the bomb in the three-dimensional space in the presence of stochastic winds. The aerodynamic coefficients for the free fall bomb are calculated through Missile Datcom computer program, however, these coefficients can be calculated either experimentally using the wind tunnel or a flight test; or mathematically through the Computational Fluid Dynamics (CFD). The stochastic wind affecting the trajectory of the bomb is defined by a velocity spectral represented by the Continuous Dryden Spectral. The contribution in this paper is the modeling and evaluation of the free fall bomb flight simulation in the presence of stochastic wind affecting the bomb flight trajectory.
\end{abstract}

Keywords: Bomb, Missile Datcom, Wind model, Mathematical Model

\section{Introduction}

For several decades, there has been an enormous increase in carrying stores (both guided and unguided weapons) on tactical fighter aircraft. In fact, many of today's aircraft carry so many stores such that pundits have remarked:"It is the stores that are carrying the aircraft! "[13]. As part of the process of store delivery prediction and verification we are developing dynamic model which can simulate the store release, and store ballistic behavior of unguided weapon. The accuracy of store delivery depends on a number of factors, including aircraft release conditions, store ejection characteristics, aerodynamic disturbances, store aerodynamic characteristics and atmospheric disturbances.

The external ballistics deals with the part of bomb motion through the external medium and its behavior during flight, i.e., from point of release to the impact point. There are different approaches to simulate bomb trajectory models like Point Mass (PM), Modified Point Mass (MPM) and 6DOF, which had developed for computing trajectory parameters and generation of Range Tables (RTs) for conventional free bombs [3]. 
Dynamic characteristics of the bomb are normally described in terms of its stability derivative values. Typically, these coefficients are experimentally obtained using wind tunnel or flight test, or mathematically using CFD. Although wind tunnel testing results in fairly accurate values of these coefficients, it is considered a complicated and time consuming method because several scale, interference and dynamic effects must be taken into account during refining its results. The second, and the most accurate method, involves flight testing the actual bomb. Unfortunately, these tests are very expensive, risky and time consuming to complete flight test program depending on number and type of required tests. The third method is the CFD which employs a combination of data sheets, linear aerodynamic theory, and empirical relations. This method provides less precision than the wind tunnel testing and takes lots of CPU time particularly if estimates of coefficients are desired over a wide range of flight conditions [8].

Nowadays, several software packages exist that allow one to obtain rapid, economical and reasonably good estimation of aerodynamic stability and control characteristics. Among these software packages are Tornado, LinAir, AVL, Digital DATCOM and MISSILE DATCOM.

MISSILE DATCOM software developed by U.S. Air Force has been widely used for preliminary estimation of bombs and missiles' aerodynamic coefficients and stability derivatives. Given the bomb configuration declared in an ASCI text file, MISSILE DATCOM will easily provide the estimation of bomb's aerodynamic coefficients and its stability derivatives for a given atmospheric conditions $[8,9]$.

The paper is organized as follows: the second section defines different coordinate systems and setting the 6DOF mathematical model for bomb trajectory, third section presents aerodynamic coefficients of bomb with a brief description about MISSILE DATCOM software with its input and output files, fourth section is devoted to wind disturbance model to study the effect of windy environment on bomb trajectory, in fifth section, simulation results are introduced for bomb flight data evaluation and bomb behavior in atmospheric disturbance. Finally, the paper concludes with a brief summery.

\section{Problem formulation}

\subsection{Coordinate Systems}

To formulate a 6DOF mathematical model of bomb, we define the following coordinate systems [1];

$\mathrm{OX}_{\mathrm{b}} \mathrm{Y}_{\mathrm{b}} \mathrm{Z}_{\mathrm{b}} \quad$ Bomb-Fixed coordinate system with its origin at bomb center of gravity (c.g.)

$\mathrm{OX}_{\mathrm{a}} \mathrm{Y}_{\mathrm{a}} \mathrm{Z}_{\mathrm{a}} \quad$ Air-trajectory reference coordinate system.

$\mathrm{OX}_{\mathrm{g}} \mathrm{Y}_{\mathrm{g}} \mathrm{Z}_{\mathrm{g}} \quad$ Earth-reference coordinate system.

These systems are related to each other by means of the Euler's angles and the transformation matrices.

Transformation between $\mathrm{OX}_{\mathrm{b}} \mathrm{Y}_{\mathrm{b}} \mathrm{Z}_{\mathrm{b}}$ and $\mathrm{OX}_{\mathrm{g}} \mathrm{Y}_{\mathrm{g}} \mathrm{Z}_{\mathrm{g}}$ systems: with the yaw angle $\psi$, pitch angle $\theta$ and roll angle $\phi$;

$$
\left(\begin{array}{l}
x_{\mathrm{g}} \\
y_{\mathrm{g}} \\
\mathrm{z}_{\mathrm{g}}
\end{array}\right)=\left(\begin{array}{ccc}
\cos \theta \cos \psi & \sin \phi \sin \theta \cos \psi-\cos \phi \sin \psi & \cos \phi \sin \theta \cos \psi+\sin \phi \sin \psi \\
\cos \theta \sin \psi & \sin \phi \sin \theta \sin \psi+\cos \phi \cos \psi & \cos \phi \sin \theta \sin \psi+\sin \phi \cos \psi \\
-\sin \theta & \sin \phi \cos \theta & \cos \phi \cos \theta
\end{array}\right)\left(\begin{array}{l}
\mathrm{x}_{\mathrm{b}} \\
y_{\mathrm{b}} \\
\mathrm{z}_{\mathrm{b}}
\end{array}\right)
$$




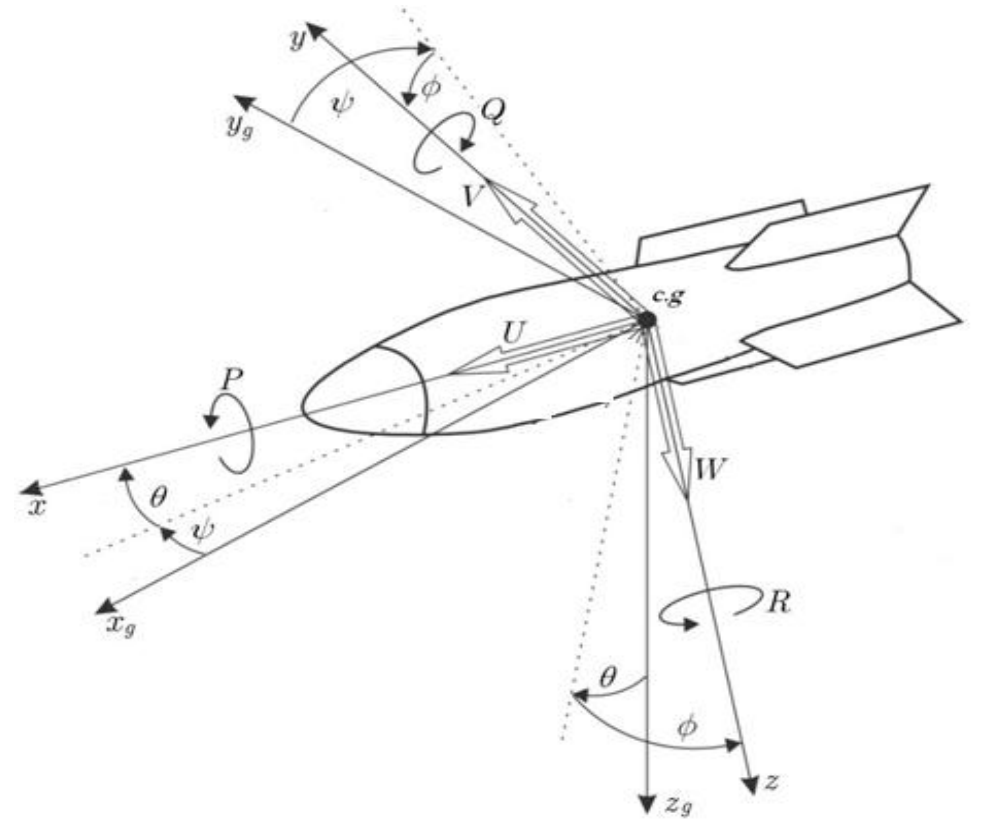

Fig.1a: Geometry between $O X_{b} Y_{b} Z_{b}$ and $O X_{g} Y_{g} Z_{g}$ systems

Transformation between $\mathrm{OX}_{b} \mathrm{Y}_{\mathrm{b}} \mathrm{Z}_{\mathrm{b}}$ and $\mathrm{OX}_{\mathrm{a}} \mathrm{Y}_{\mathrm{a}} \mathrm{Z}_{\mathrm{a}}$ systems: with the angle of sideslip $\beta$ and angle of attack $\alpha$;

$$
\left(\begin{array}{l}
x_{a} \\
y_{a} \\
z_{a}
\end{array}\right)=\left(\begin{array}{ccc}
\cos \alpha \cos \beta & \sin \beta & \sin \alpha \cos \beta \\
-\cos \alpha \sin \beta & \cos \beta & -\sin \alpha \sin \beta \\
-\sin \alpha & 0 & \cos \alpha
\end{array}\right)\left(\begin{array}{l}
x_{b} \\
y_{b} \\
z_{b}
\end{array}\right)
$$

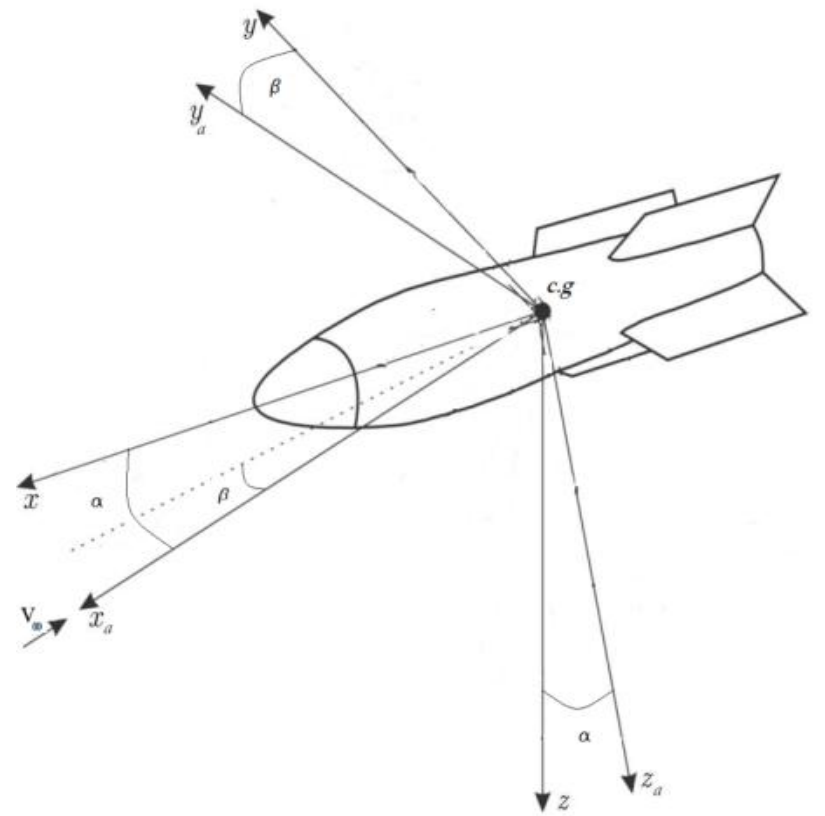

Fig.1b: Geometry between $O X_{b} Y_{b} Z_{b}$ and $O X_{a} Y_{a} Z_{a}$ systems

\subsection{Equations of Motion}

In order to describe the bomb flight path, 6DOF model is constructed under the following assumptions $[1,7]$ :

1. The bomb is considered as a rigid body.

2. The Earth is considered flat, non rotary and the gravity acceleration is considered constant. 
3. The bomb mass and moment of inertia are considered constant during any particular dynamic analysis and constant position of center of mass.

4. Both XZ plane and XY plane are planes of bomb symmetry.

5. Small azimuth angle.

6. The bomb is considered non-spinning.

7. Bomb is released from level flight.

Starting from Newton's second low of motion, "The summation of all external forces and moments acting on a body must equal to the time rate of change of its momentum and angular momentum respectively." [1, 7 and 12], it is expressed in body frame by:

$$
\begin{aligned}
& \sum \overline{\mathbf{F}}=\left.\frac{\mathrm{d}(\mathrm{m} \overline{\mathbf{V}})}{\mathrm{dt}}\right|_{\mathrm{g}}=\mathrm{m}\left(\frac{\mathrm{d} \overline{\mathbf{V}}}{\mathrm{dt}}+\omega_{\mathrm{b}} \times \overline{\mathbf{V}}\right) \\
& \sum \overline{\mathbf{M}}=\left.\frac{\mathrm{d}(\overline{\mathbf{H}})}{\mathrm{dt}}\right|_{\mathrm{g}}=\left(\frac{\mathrm{d} \overline{\mathbf{H}}}{\mathrm{dt}}+\omega_{\mathrm{b}} \times \overline{\mathbf{H}}\right)
\end{aligned}
$$

Where $\omega_{\mathrm{b}}=\left[\begin{array}{lll}\mathrm{p} & \mathrm{q} & \mathrm{r}\end{array}\right]^{\mathrm{T}}, \overline{\mathbf{H}}=\mathbf{I} \boldsymbol{\omega}_{\mathbf{b}}$ and $\mathbf{I}$ is moment of inertia matrix.

Euler angles represent three successful rotations (roll, pitch and yaw). There is a direct relationship between Euler angles and the angular velocity of the bomb around its body axes. The rates of change of the attitude angles can be obtained as:

$$
\left(\begin{array}{c}
\dot{\phi} \\
\dot{\theta} \\
\dot{\psi}
\end{array}\right)=\left(\begin{array}{ccc}
1 & \sin \phi \tan \theta & \cos \phi \tan \theta \\
0 & \cos \phi & -\sin \phi \\
0 & \sin \phi / \cos \theta & \cos \phi / \cos \theta
\end{array}\right)\left(\begin{array}{l}
\mathrm{p} \\
\mathrm{q} \\
\mathrm{r}
\end{array}\right)
$$

To fully describe the bomb trajectory, both orientation and position with respect to inertial axes should be defined. The bomb linear velocities $\mathbf{V}=\left[\begin{array}{lll}\mathbf{u} & \mathrm{V} & \mathrm{w}\end{array}\right]^{\mathrm{T}}$ must be converted into linear position rates in earth axes by applying transformation from body axes to earth axes.

$$
\begin{aligned}
& \left(\begin{array}{c}
\dot{x}_{\mathrm{g}} \\
\dot{\mathrm{y}}_{\mathrm{g}} \\
\dot{\mathrm{z}}_{\mathrm{g}}
\end{array}\right) \\
& =\left(\begin{array}{ccc}
\cos \theta \cos \psi & \sin \phi \sin \theta \cos \psi-\cos \phi \sin \psi & \cos \phi \sin \theta \cos \psi+\sin \phi \sin \psi \\
\cos \theta \sin \psi & \sin \phi \sin \theta \sin \psi+\cos \phi \cos \psi & \cos \phi \sin \theta \sin \psi+\sin \phi \cos \psi \\
-\sin \theta & \sin \phi \cos \theta & \cos \phi \cos \theta
\end{array}\right)\left(\begin{array}{c}
\mathrm{u} \\
\mathrm{v} \\
\mathrm{W}
\end{array}\right)
\end{aligned}
$$

Forces acting on bomb are aerodynamic forces and weight force. Components of these forces are represented in body frame as follows:

$$
\begin{aligned}
& \left(\begin{array}{l}
\mathrm{W}_{\mathrm{x}} \\
\mathrm{W}_{\mathrm{y}} \\
\mathrm{W}_{\mathrm{z}}
\end{array}\right)=\left(\begin{array}{c}
-\mathrm{mg} \sin \theta \\
0 \\
\mathrm{mg} \cos \theta
\end{array}\right) \\
& \left(\begin{array}{l}
\mathrm{R}_{\mathrm{x}} \\
\mathrm{R}_{\mathrm{y}} \\
\mathrm{R}_{\mathrm{z}}
\end{array}\right)=\frac{1}{2} \rho \mathrm{V}^{2} \mathrm{~S}\left(\begin{array}{c}
-\mathrm{C}_{\mathrm{x}} \\
\mathrm{C}_{\mathrm{y}} \\
-\mathrm{C}_{\mathrm{z}}
\end{array}\right) \\
& \mathrm{X}=-m g \sin \theta-\mathrm{C}_{\mathrm{x}} \frac{1}{2} \rho \mathrm{V}^{2} \mathrm{~S} \\
& \mathrm{Y}=\mathrm{C}_{\mathrm{y}} \frac{1}{2} \rho \mathrm{V}^{2} \mathrm{~S}
\end{aligned}
$$




$$
\mathrm{Z}=\operatorname{mg} \cos \theta-\mathrm{C}_{\mathrm{z}} \frac{1}{2} \rho \mathrm{V}^{2} \mathrm{~S}
$$

Where force vector is $\sum \overline{\mathrm{F}}=\left[\begin{array}{lll}\mathrm{X} & \mathrm{Y} & \mathrm{Z}\end{array}\right]^{\mathrm{T}}$, the weight force $\mathrm{W}=\left[\begin{array}{lll}\mathrm{W}_{\mathrm{x}} & \mathrm{W}_{\mathrm{y}} & \mathrm{W}_{\mathrm{z}}\end{array}\right]^{\mathrm{T}}$ and aerodynamic force vector is $R=\left[\begin{array}{lll}R_{x} & R_{y} & R_{z}\end{array}\right]^{T}$.

On other hand, moments acting on bomb are only the aerodynamic moments which are represented in body frame as follows:

$$
\left(\begin{array}{c}
L \\
M \\
N
\end{array}\right)=\frac{1}{2} \rho V^{2} S D\left(\begin{array}{c}
0 \\
C_{m} \\
C_{n}
\end{array}\right)
$$

Where the moment vector is $\sum \overline{\mathrm{M}}=\left[\begin{array}{lll}\mathrm{L} & \mathrm{M} & \mathrm{N}\end{array}\right]^{\mathrm{T}}$.

Considering assumptions, the 6DOF mathematical model will be as follows:

Force equations;

$$
\begin{aligned}
& \dot{\mathrm{u}}=\frac{\left(-\mathrm{mgsin} \theta-\mathrm{C}_{\mathrm{x}} \frac{1}{2} \rho \mathrm{V}^{2} \mathrm{~S}\right)}{\mathrm{m}}+\mathrm{rv}-\mathrm{qw} \\
& \dot{\mathrm{v}}=\frac{\left(\mathrm{C}_{\mathrm{y}} \frac{1}{2} \rho \mathrm{V}^{2} \mathrm{~S}\right)}{\mathrm{m}}-\mathrm{ru} \\
& \dot{\mathrm{w}}=\frac{\left(\mathrm{mg} \cos \theta-\mathrm{C}_{\mathrm{z}} \frac{1}{2} \rho \mathrm{V}^{2} \mathrm{~S}\right)}{\mathrm{m}}+\mathrm{qu}
\end{aligned}
$$

Moment equations;

$\mathrm{C}_{\mathrm{l}}=0 \Rightarrow \dot{\mathrm{p}}=0, \mathrm{p}_{0}=0 \Rightarrow \mathrm{p}=0$

$\dot{\mathrm{q}}=\frac{1}{\mathrm{I}_{\mathrm{yy}}} \mathrm{C}_{\mathrm{m}} \frac{1}{2} \rho \mathrm{V}^{2} \mathrm{SD}$

$\dot{\mathrm{r}}=\frac{1}{\mathrm{I}_{\mathrm{zz}}} \mathrm{C}_{\mathrm{n}} \frac{1}{2} \rho \mathrm{V}^{2} \mathrm{SD}$

Kinematic equations;

$\dot{\phi}=\operatorname{rtan} \theta$

$\dot{\theta}=\mathrm{q}$

$\dot{\psi}=\mathrm{r} \frac{1}{\cos \theta}$

Navigation equations;

$\dot{\mathrm{x}}_{\mathrm{g}}=\mathrm{u} \cos \theta-\mathrm{v} \psi+\mathrm{w} \sin \theta$

$\dot{\mathrm{y}}_{\mathrm{g}}=\mathrm{u} \psi \cos \theta+\mathrm{v}+\mathrm{w} \psi$

$\dot{\mathrm{z}}_{\mathrm{g}}=-\mathrm{u} \sin \theta+\mathrm{w} \cos \theta$

The model bomb characteristics are shown in Table $1[10,11]$.

Table 1 Bomb characteristics

\begin{tabular}{c|c|c|c}
\hline \hline Mass (m) & $239.5[\mathrm{Kg}]$ & $\mathrm{I}_{\mathrm{xx}}$ & $2.35\left[\mathrm{Kg} \mathrm{m}^{2}\right]$ \\
\hline Diameter(D) & $0.273[\mathrm{~m}]$ & $\mathrm{I}_{\mathrm{yy}}$ & $56.74\left[\mathrm{Kg} \mathrm{m}^{2}\right]$ \\
\hline Length (l) & $2.3[\mathrm{~m}]$ & $\mathrm{I}_{\mathrm{zz}}$ & $56.74\left[\mathrm{Kg} \mathrm{m}^{2}\right]$ \\
\hline \hline
\end{tabular}




\section{Aerodynamic coefficients for forces and moments}

The aerodynamic coefficients $C_{x}, C_{y}, C_{z}, C_{l}, C_{m}$, and $C_{n}$ are called total coefficients of forces and moments, they are primarily function of Mach number, Reynolds number, angle of attack and side slip angle and are secondary functions of time rate of change of side slip angle and angle of attack.

These coefficients are calculated using MISSILE DATCOM program which is necessary to quickly and economically estimate the aerodynamics of a wide variety of missile configuration designs $[2,8]$. The fundamental purpose of MISSILE DATCOM is to provide an aerodynamic design tool which has the accuracy suitable for preliminary design, and the capability for the user to easily substitute methods to fit specific applications [9].

Inputs to the program are grouped by "case". A "case" consists of a set of input cards which define the flight conditions and geometry to be run. Provisions are made to allow multiple cases to be run. The output file has three main sections: First, an analysis by the input error checking routine is provided. It lists all input cards provided by the user and identifies any input errors detected. Second, a listing of all input cards, grouped by case, are provided; included in this output is an error analysis from the major input error routine MAJERR. Finally, the total configuration aerodynamics is provided in summary form; one page of aerodynamic output is supplied for each Mach number specified. The MAJERR results and the total configuration aerodynamics results are listed in succession for each case [9]. The following figures (Fig.2.a-e) show the aerodynamic coefficient curves for the model bomb under study.

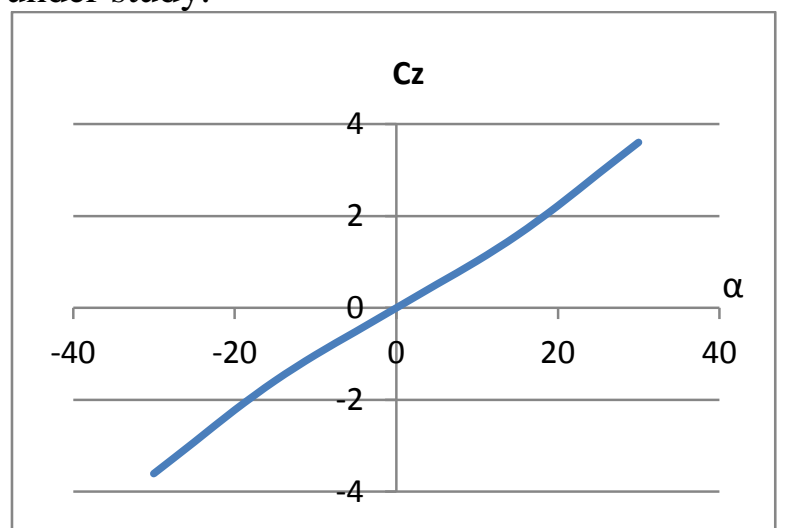

Fig.2a: Lift Coefficient

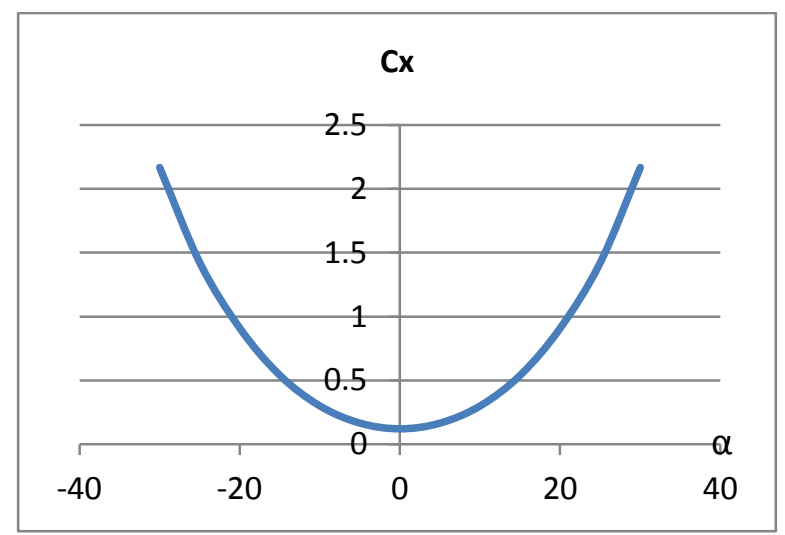

Fig.2b: Drag coefficient

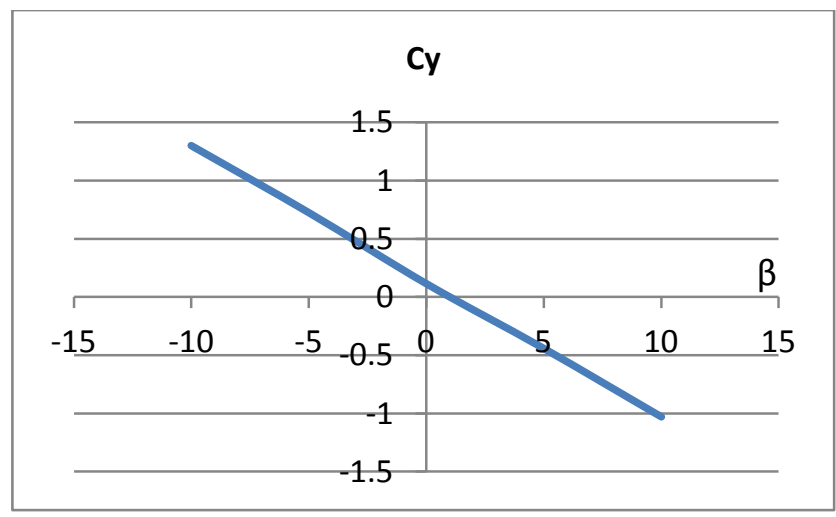

Fig.2c: Side Force coefficient 


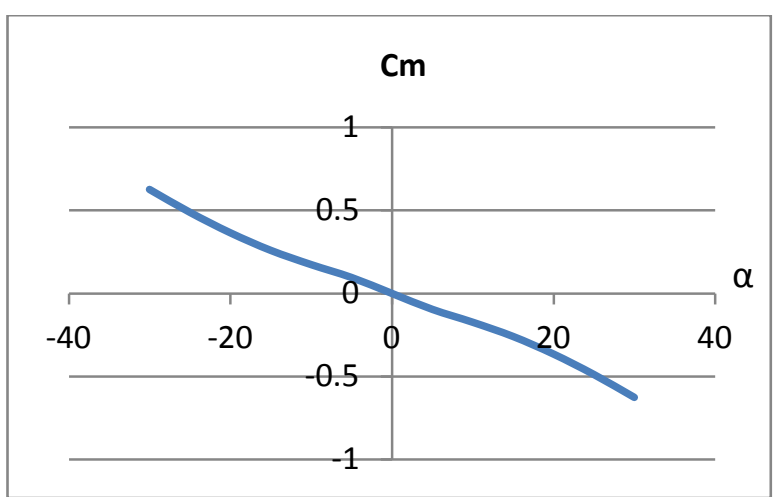

Fig.2d: Pitch moment coefficient

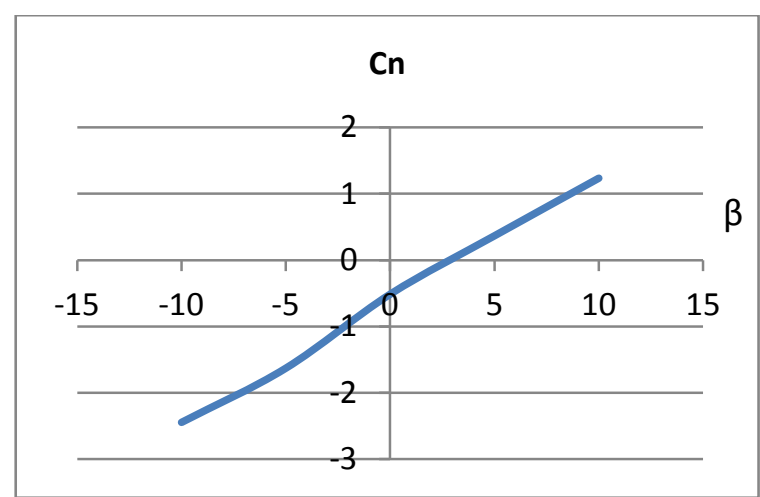

Fig.2e: Yaw moment coefficient

\section{Wind disturbance model}

Wind with its stochastic nature has an effect on the bomb flight parameters. This wind affects the relative velocity of body with respect to surrounding air and hence affects the aerodynamic forces and moments acting on bomb. In this paper we are not concerned with studying the wind itself, but its influence on bomb trajectory. To generate a turbulence signal with the correct characteristics, a unit variance, band-limited white noise signal is passed through or used in the appropriate filters. These filters are ultimately derived from the turbulence spectra.

Three forms of filters are covered in the military references MIL-HDBK-1797 and MIL-F-8785C [4, 5 and 6]:

- Continuous Von Kármán,

- Continuous Dryden, and

- $\quad$ Discrete Dryden.

Components of wind using Continuous Dryden Spectrum are shown in Fig.3.

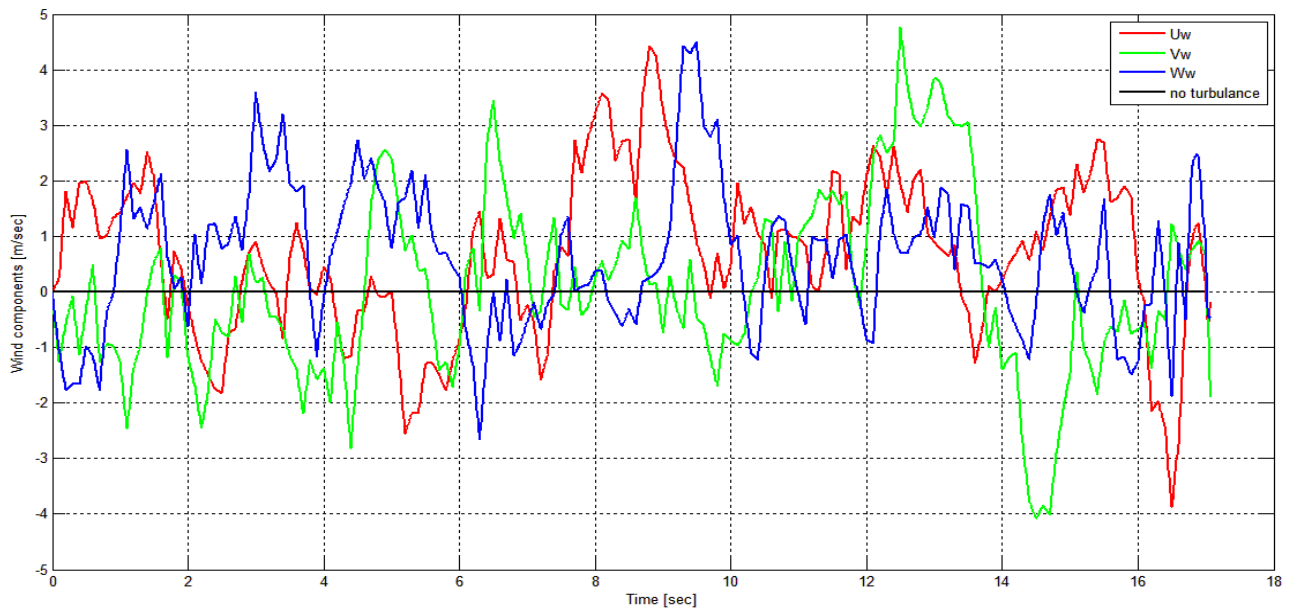

Fig.3: Wind components

\section{Simulation Results}

Release of bomb is simulated using MATLAB and SIMULINK. First, simulation results were compared against reference data, part of these data is in reference [11], to validate the constructed model, and then we study the effect of disturbance on bomb trajectory. 


\section{Case I: Bomb flight evaluation}

The bomb is released at different velocities $(100[\mathrm{~m} / \mathrm{sec}], 200[\mathrm{~m} / \mathrm{sec}]$ and $300[\mathrm{~m} / \mathrm{sec}])$ each at different altitudes $(300[\mathrm{~m}]$ to $3300[\mathrm{~m}])$ and compared with reference data.

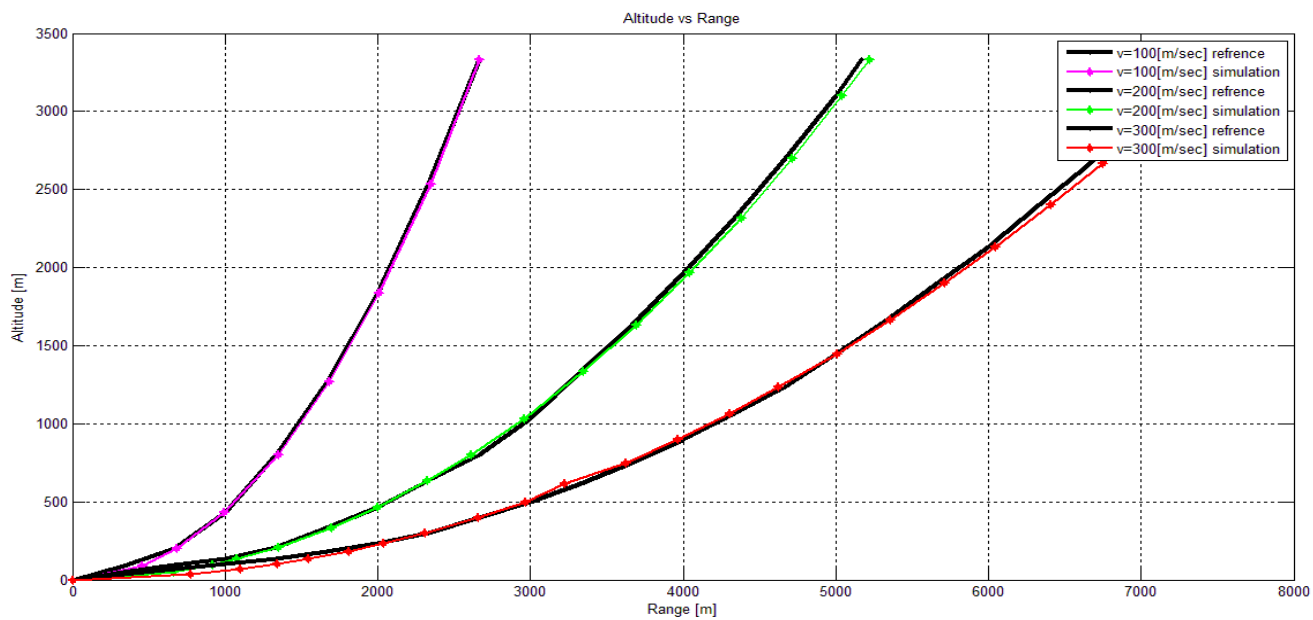

Fig.4: Release curves results vs. reference data

The percentage range error in simulation results does not exceed $\pm 2 \%$ when bomb is released from altitudes $(300[\mathrm{~m}]$ to $3300[\mathrm{~m}])$. Fig.4 shows the percentage error in range.

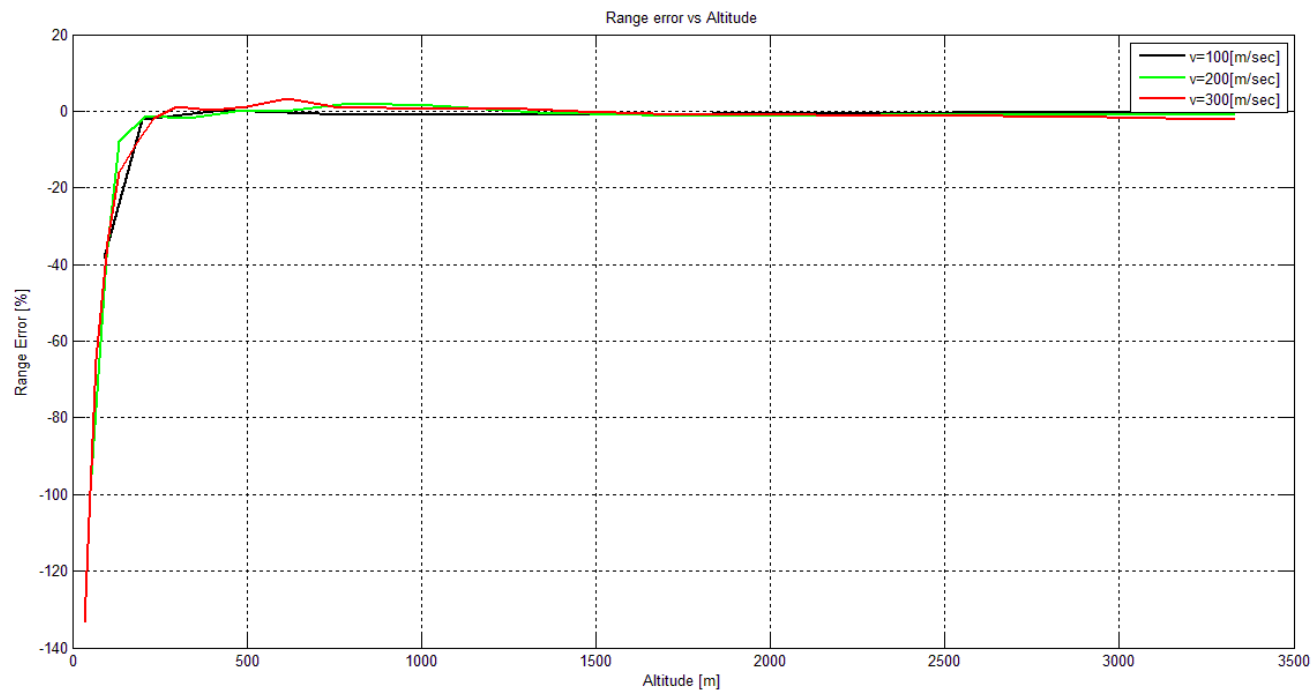

Fig.5: Percentage error in range

\section{Case II: Bomb release simulation in windy environment}

It was assumed that a bomb is released from altitude $1500[\mathrm{~m}]$, and the aircraft kept flying at speed $250[\mathrm{~m} / \mathrm{sec}]$. Subsequent figures (Fig.6.a-g) present the flight trajectory and flight parameters against time and windy environment effect on bomb flight. 

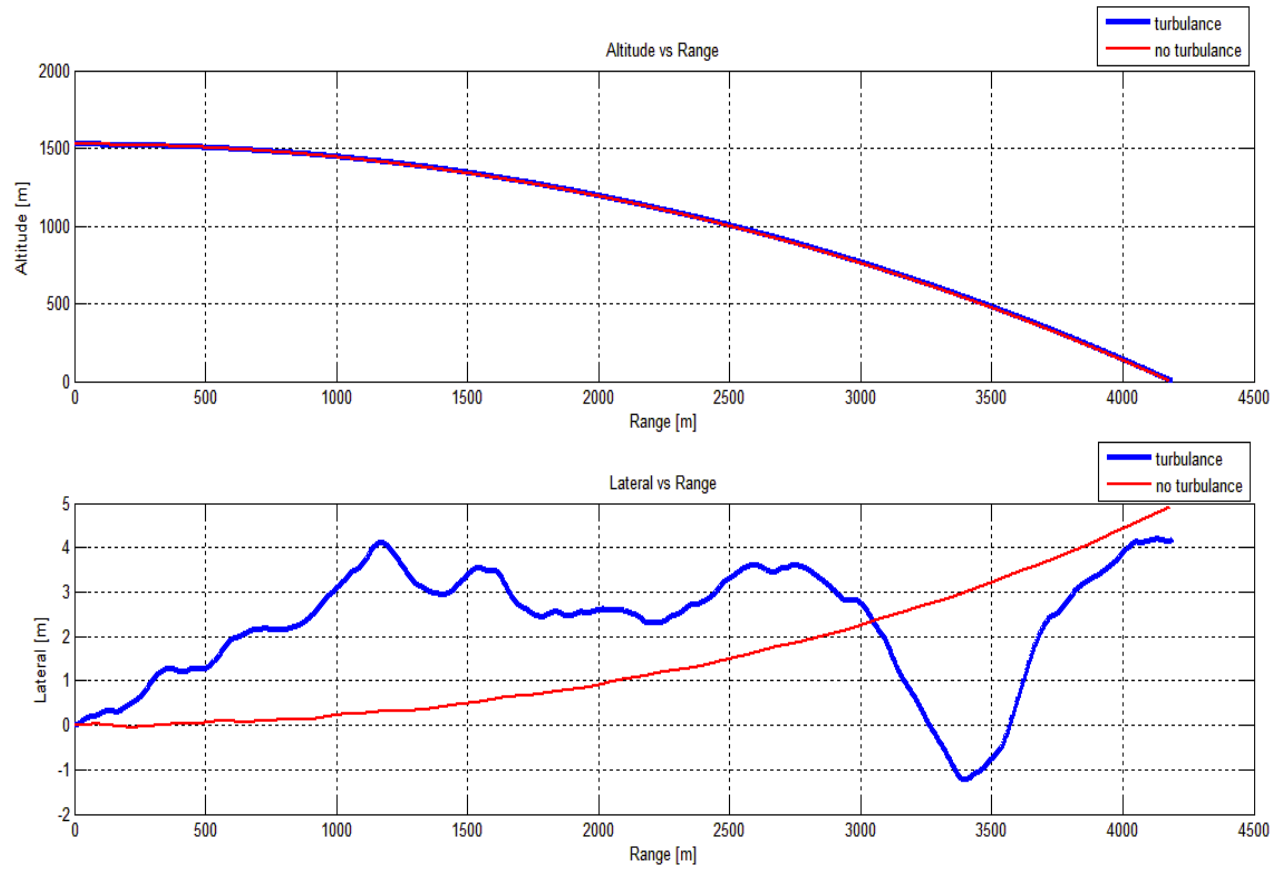

Fig.6a: Effect of wind on bomb longitudinal and lateral path

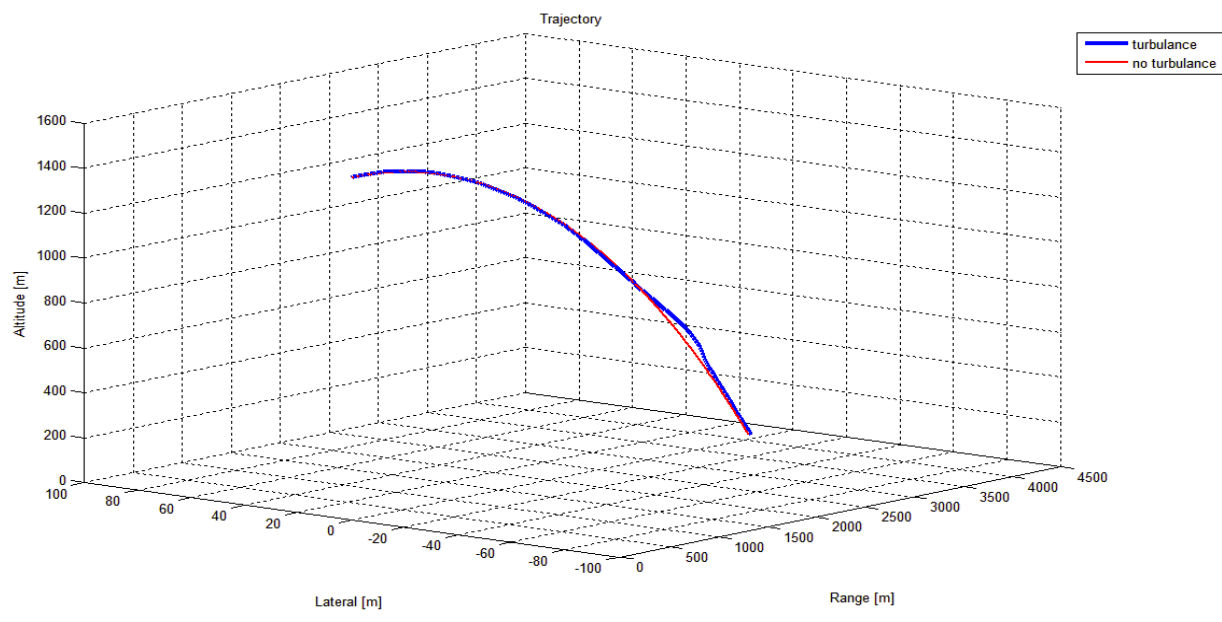

Fig.6b: Effect of wind on bomb trajectory

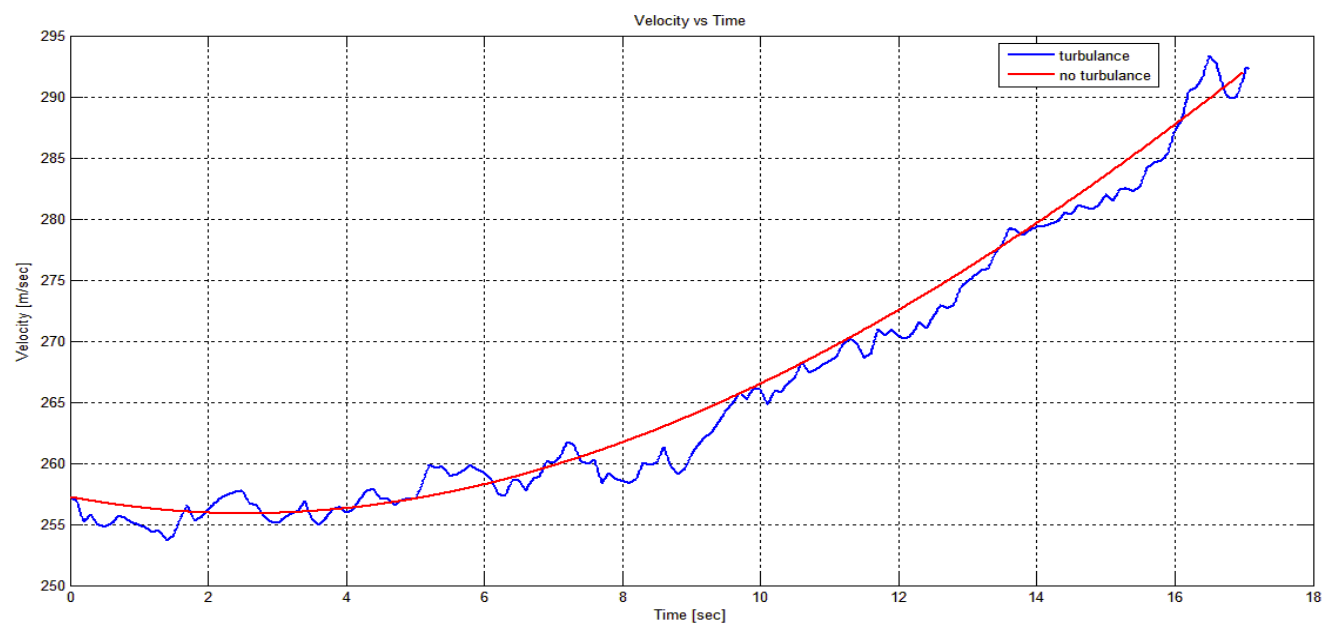

Fig.6c: Effect of wind on bomb velocity 


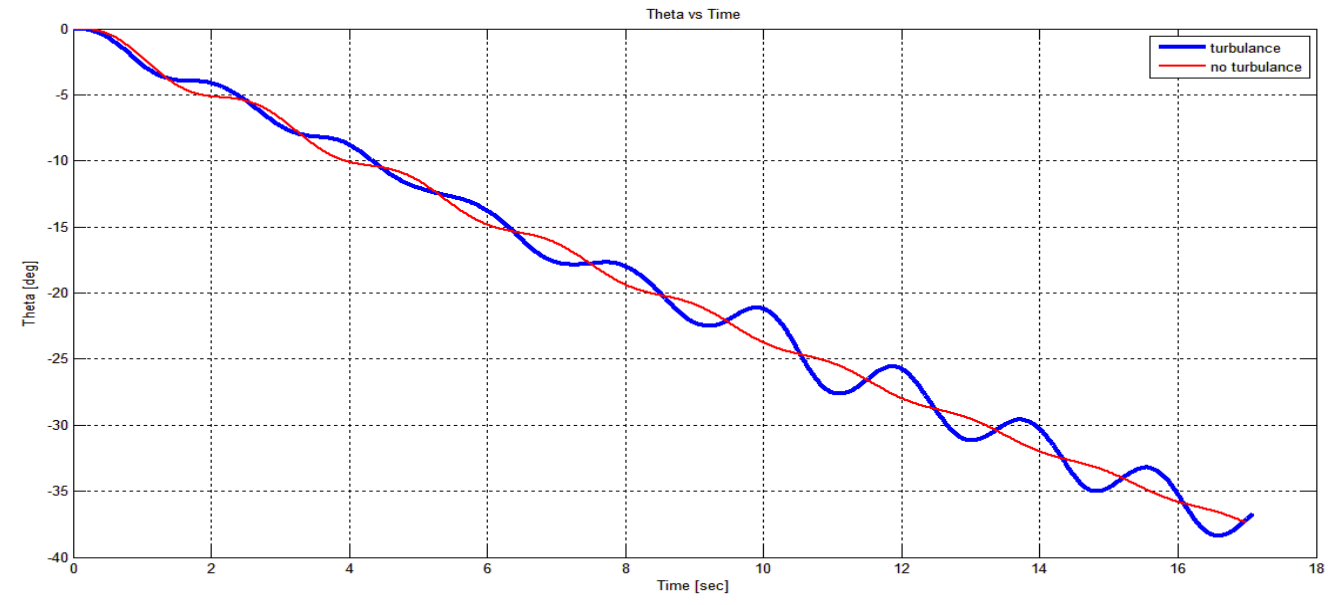

Fig.6d: Effect of wind on bomb pitch angle

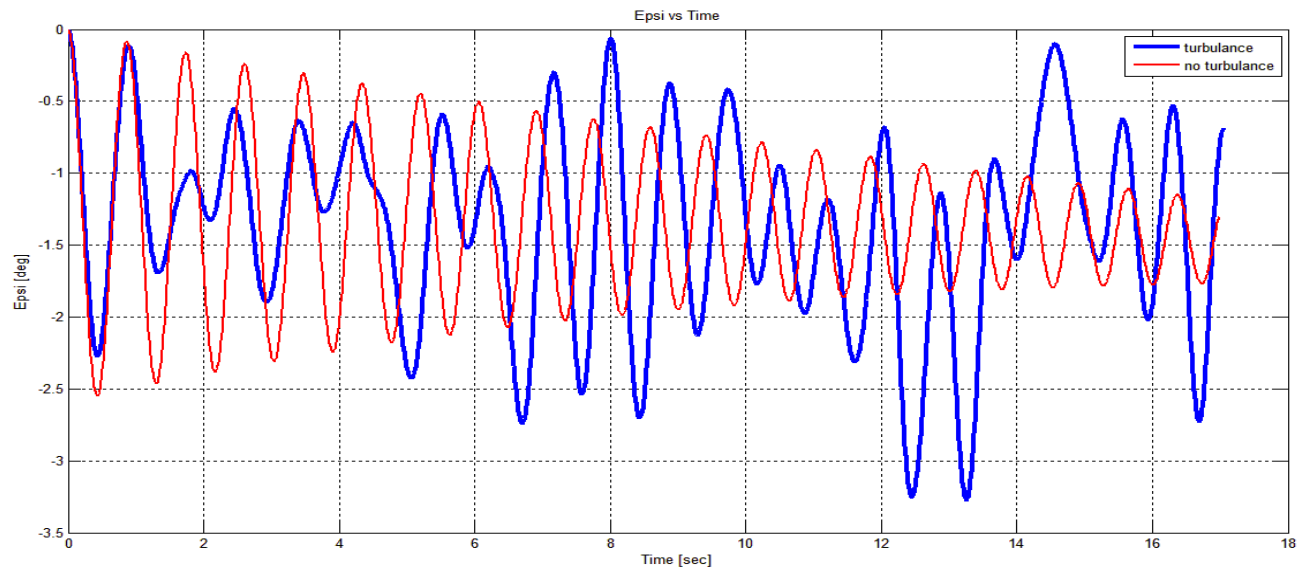

Fig.6e: Effect of wind on bomb yaw angle

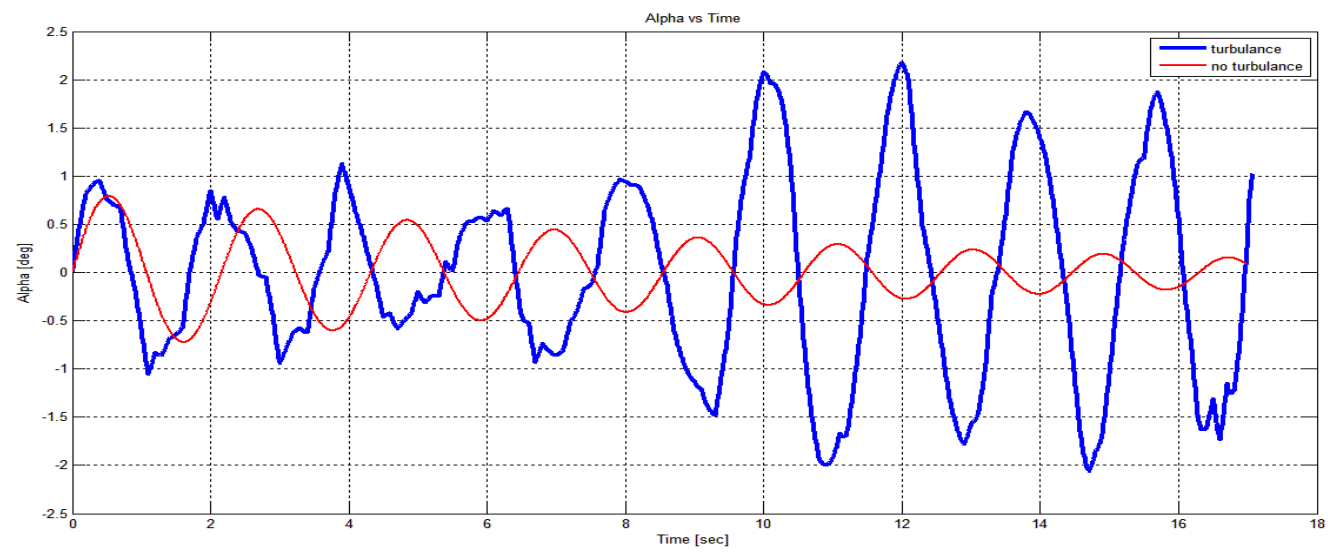

Fig.6f: Effect of wind on bomb angle of attack 


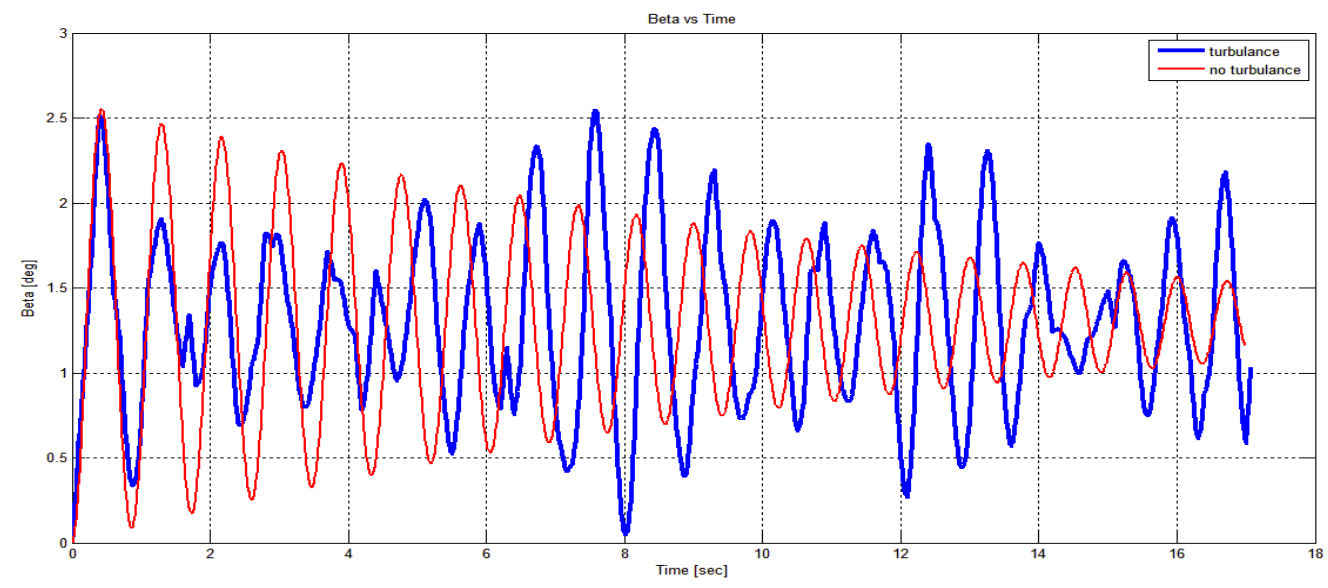

Fig.6g: Effect of wind on bomb sideslip angle

From the previous figures, it is clear that wind affects bomb flight parameters. Figures (Fig.6.a and Fig.6.b) show the bomb trajectory in air and the effect of wind on bomb trajectory shape. Fig.6.c shows the effect of wind on velocity where its value in windy environment vibrates around its value in no-turbulence. Also, the wind affects the value of pitch angle as it swings about its value in no- turbulence curve (Fig.6.d). Figures (Fig.6.e-g) show the wind effect on the behavior of yaw angle, angle of attack and sideslip angle that posses oscillations due to wind and make bomb deviates from vertical plane of release, but the bomb remains stable.

\section{Conclusion}

A 6DOF nonlinear dynamic model of bomb had built to simulate the bomb trajectory. The MISSILE DATCOM program is used to get aerodynamic coefficients of bomb configuration. In addition to MISSILE DATCOM, MATLAB is used to simplify, accelerate the modeling process and create open loop model. This open loop model is required for analysis and in future use in modeling flight bomb dynamics and control system design. The conducted analysis has proved that the effect of wind on the accuracy of bomb release is essential and should be taken into account when planning the bombing.

\section{References}

[1] Kowaleczko, G., Zyluk, A., "Influence of Atmospheric Turbulence on Bomb Release," ", Journal of Theoretical and Applied Mechanics, JTAM-47," Warsaw, 2009, pp. 69-90.

[2] Mansor, S., Ishak, I.S., Omar, W.Z., Rahman, A.B., Shamsudin, M.A., "Evaluation of Aerodynamic Derivatives of MK82 Bomb from Wind Tunnel Testing and Empirical Methods," ", International Conference on Mechanical, Automotive and Aerospace Engineering, ICMAAE-2, ”July 2013.

[3] Chand, K.K., Panda, H.S., "Mathematical Model to Simulate the Trajectory Elements of an Artillery Projectile Proof Shot," ", Defense Science Journal," Jan 2007, pp. 139-148.

[4] Gage, S., "Creating a Unified Graphical Wind Turbulence Model from Multiple Specifications," ", AIAA Modeling and Simulation Technologies Conference and Exhibit, AIAA 2003-5529”, August, 2003.

[5] U.S. Military Handbook MIL-HDBK-1797, 19December 1997.

[6] U.S. Military Specification MIL-F-8785C, 5 November 1980.

[7] Saad, M., "Flight Control System Design and Simulation,"," Military Technical Collage, M.Sc." Cairo, 2013. 
[8]Elharouny, A. S., Youssef, A.M., Zakaria, M.Y., Abdelhameed, M.M., "Procedures For Building Aerodynamic Models for Small Unmanned Aerial Vehicle," ", Proceeding of the International Conference on Applied Mechanics and Mechanical Engineering, AMME-15" May, 2012.

[9] Blake, W.B.,’Missile Datcom, User' Manual-1997 FORTRAN 90 Revision”, AFRL-VA-WP-TR-1998-3009, Feb, 1998.

[10] Shilo, M.A. "Six Degree of Freedom Flight Dynamic Model of MK82 Store", "Defense Science and Technology Orgnisation, Aeronautical Research Laboratory, Victoria", Jan, 1994.

[11] Marvin, k., Wrenn, A., "MK81 and Mk82 Bomb Release Curves", "United States Orgnisation Laboratory, NOLTR 65-230”, May, 1966.

[12] Gkritizapis, D.N., Panagiotopoulos, E.E., Margaris, D.P., Papanikas, D.G., "Modified Linear Theory for Spinning or Non-spinning Projectile", "The Open Mechanics Journal", Jan, 2008, pp. 6-11.

[13] Arnold, R.J., Knight, J.B., "Weapon Delivery and Ballistic Flight Testing”, "Flight test technique series, VOL-10", July, 1992. 